\title{
Livermore reopens plutonium building amid danger claims
}

San Francisco. The Lawrence Livermore Laboratory in California has reopened its plutonium building after a six-month shutdown following the discovery of major deficiencies in its safety practices. But the move has revived efforts by local critics to shut down the federal defence laboratory's activities involving plutonium machining and experimentation.

The laboratory announced in early December that it was calling workers back to the high-security plutonium building after the shutdown, which had led to between 30 and 40 workers being moved to other parts of the laboratory. Officials said they had implemented improvements designed to increase the safety with which the laboratory's 880 pounds (about $360 \mathrm{~kg}$ ) of the radioactive material is handled and stored.

The facility was closed last April by the Defense Nuclear Facilities Safety Board after confirmation of safety deficiencies. These included the failure in early April to carry out an important inspection of the air pressure inside the building, and a lack of procedures to ensure the testing of other safety systems. The board also raised questions over safety training, inadequate staffing and ambiguities in safety procedures.

Laboratory officials say that they have investigated the problems revealed by the safety board, and have added improved safety equipment to the building, including a \$1.2-million emergency generator and a $\$ 1.2$-million ventilation system. Both the sprinkler and nuclear accident alarm systems have also been strengthened.

The workers who had been moved began returning to the plutonium area in October, and the facility reopened last month. But critics argued that there was no reason to reopen the building and to revive the hazard of plutonium handling on the site. "While the facility was shut down for six months, that was an opportunity to evaluate the need for it at all during the post-Cold-War era," says Marylia Kelley, spokeswoman for Tri-Valley Citizens Against a Radioactive Environment in Livermore.

Kelley points out that there have been continuing safety problems at the plutonium facility. She lists some of the potential dangers as earthquakes, fires, and the bulging storage canisters cited in a 1994 Department of Energy vulnerability assessment. She says the shutdown has given her group ammunition enabling it to press harder for a permanent closure, and that it has already submitted a petition with 3,000 signatures urging the halt of the plutonium manufacturing demonstration project. "We believe we are close to getting it shut down permanently," says Kelley. Sally Lehrman

\section{Kidnappings 'must not deter' sponsors of research trips}

London. Organizations backing a British student-led research expedition to Indonesia whose members were kidnapped last week by separatist rebels in the eastern province of Irian Jaya say the experience will not deter them from funding similar projects in the future.

Colin Bibby, conservation director of Birdlife International, which awarded $£ 3,000$ (US\$4,650) for the five-month project to catalogue some of the biodiversity of Irian Jaya, says his organization will review its procedures. But he says it would be a tragedy if fewer young people volunteered for overseas expeditions as a result of the experience of the expedition, known as Lorentz 95. "Most of our pioneering studies have been performed by young people," he says. "They are flexible, find it easier to overcome cultural barriers and can quickly get on with people."

The $£ 20,000$ expedition, which was organized by four recent graduates of the University of Cambridge, had also received advice and financial support from the Royal Botanic Gardens at Kew and the Royal Geographical Society (RGS).

Shane Winser, head of the RGS's Expedition Advisory Centre, says she hopes the kidnappings do not put off parents from letting young people from taking part in research expeditions. Few of the 400 to 500 expeditions supported annually by the RGS are carried out by postgraduate researchers, she says. "In our experience, there is a greater risk from road accidents and malaria than from getting kidnapped."

Twenty-four expedition members including local researchers, support staff and officials from the World Wide Fund for Nature (WWF) - were captured by the Free Papua Movement (OPM), a 30-yearold organization that has waged a low-key campaign for the region to break away from Indonesia and join with its geographical and cultural neighbour, Papua New Guinea.

The OPM is opposed to the Indonesian government's policy of transferring people from overcrowded parts of the archipelago to Irian Jaya. The movement also wants a larger share of the wealth from gold and copper mines on the southwest coast of Irian Jaya owned by US companies.

Irian Jaya, a Dutch colony until the early $1960 \mathrm{~s}$, is home to a number of native tribes with little interest in modern technology. They fight with wooden bows and arrows, and travel the waterways in canoes built from ancient designs. These people, however, are believed to be among the most linguistically sophisticated in the world.

Irian Jaya is one the few global regions not to have been studied for its biological diversity - the last major expedition is believed to have taken place in 1911 . Members of Lorentz 95 were working inside a 1.5-million-hectare region of Irian Jaya that is the subject of negotiations between WWF and the Indonesian government on designation as a national park.

But according to some observers, the OPM is concerned about plans for the park.

\section{IMAGE UNAVAILABLE FOR COPYRIGHT REASONS}

Members of the movement fear that the Indonesian government may be using its tentative backing for a conservation area to consolidate its grip on the region.

The kidnappings have also raised the question of the safety of fieldworkers operating in sensitive parts of the world.

But Matthew Reynolds, a postgraduate student in development studies at the University of East Anglia and one of the founders of Lorentz 95, says the local political situation "was not considered to be dangerous." Reynolds, who was unable to travel to Indonesia for health reasons, says "Irian Jaya is half the size of Europe. The rebel groups are small, disorganized and equipped with bows and arrows. We figured the chance of coming across them would be very remote."

Bibby says the fact that Lorentz 95 was "an exceptionally well-thought out project" would not alone guarantee support. Backing from local authorities was essential, as was involvement from local researchers and the ability to work in safety.

Birdlife International, he points out, previously turned down two "first class research projects" to Rwanda and Burundi, well before the current civil wars, on the grounds that both regions were not considered safe to work in.

The organizers of Lorentz 95, he says, had good local contacts and made an effort to involve researchers from the Indonesian Institute of Biological Sciences. "They were better organized and better prepared than anything I've seen."

Ehsan Masood 